\title{
Early Systemic Failure After Preoperative Chemoradiotherapy for the Treatment of Patients With Rectal Cancer
}

\author{
Taesun Choi, Se-Jin Baek, Jung Myun Kwak, Jin Kim, Seon-Hahn Kim \\ Department of Surgery, Korea University College of Medicine, Seoul, Korea
}

Purpose: Distant metastasis can occur early after neoadjuvant chemoradiotherapy (CRT) in patients with rectal cancer. This study was conducted to evaluate the clinical characteristics of patients who developed early systemic failure.

Methods: The patients who underwent neoadjuvant CRT for a rectal adenocarcinoma between June 2007 and July 2015 were included in this study. Patients who developed distant metastasis within 6 months after CRT were identified. We compared short- and long-term clinicopathologic outcomes of patients in the early failure (EF) group with those of patients in the control group.

Results: Of 107 patients who underwent neoadjuvant CRT for rectal cancer, 7 developed early systemic failure. The lung was the most common metastatic site. In the EF group, preoperative carcinoembryonic antigen was higher $(5 \mathrm{mg} / \mathrm{mL}$ vs. 2 $\mathrm{mg} / \mathrm{mL}, \mathrm{P}=0.010)$, and capecitabine as a sensitizer of CRT was used more frequently $(28.6 \% \mathrm{vs.} 3 \%, \mathrm{P}=0.002)$. Of the 7 patients in the EF group, only 4 underwent a primary tumor resection (57.1\%), in contrast to the $100 \%$ resection rate in the control group $(\mathrm{P}<0.001)$. In terms of pathologic outcomes, $\mathrm{ypN}$ and TNM stages were more advanced in the EF group $(\mathrm{P}<0.001$ and $\mathrm{P}=0.047$, respectively), and numbers of positive and retrieved lymph nodes were much higher $(\mathrm{P}<$ 0.001 and $\mathrm{P}=0.027$, respectively).

Conclusion: Although early distant metastasis after CRT for rectal cancer is very rare, patients who developed early metastasis showed a poor nodal response with a low primary tumor resection rate and poor oncologic outcomes.

\section{Keywords: Rectal neoplasms; Chemoradiotherapy; Neoadjuvant therapy; Distant metastasis; Systemic failure}

\section{INTRODUCTION}

Over the last several decades, preoperative chemoradiotherapy (CRT) has been accepted as a standard treatment for patients with locally advanced rectal cancer because it can reduce local recurrence postoperatively and enable sphincter-saving surgery in

Received: April 21, 2018 • Accepted: August 28, 2018

Correspondence to: Se-Jin Baek, M.D.

Department of Surgery, Korea University College of Medicine, 73 Inchon-ro, Seongbuk-gu, Seoul 02841, Korea

Tel: +82-2-920-6284, Fax: +82-2-928-1631

E-mail: xezin@korea.ac.kr

ORCID code: https://orcid.org/0000-0002-3185-8777

- This study was presented as a poster at the Annual Scientific Meeting of The American Society of Colon \& Rectal Surgeons (ASCRS), April 30-May 4, 2016, Los Angeles, CA, USA.

(C) 2019 The Korean Society of Coloproctology

This is an open-access article distributed under the terms of the Creative Commons Attribution NonCommercial License (http://creativecommons.org/licenses/by-nc/4.0) which permits unrestricted noncommercial use, distribution, and reproduction in any medium, provided the original work is properly cited. some patients who had been ineligible for the procedure before CRT $[1,2]$. National Comprehensive Cancer Network guidelines recommend preoperative radiotherapy or CRT for all patients with rectal cancer suspected to be greater than stage T3 or with lymph node (LN) metastasis on preoperative evaluation [3].

Concern for failure of systemic control of the disease during CRT remains an issue in the treatment of patients with cancer because radiotherapy only involves local treatment of the disease and rectal cancer in patients who are eligible for preoperative radiotherapy is locally advanced. Moreover, a long period of about three to four months is typical between diagnosis and surgery. Thus, many other chemotherapy regimens added to fluorouracilbased CRT have been suggested in an effort to enhance systemic control during CRT or within the window from radiotherapy to surgery $[4,5]$.

Nevertheless, reports of early distant metastasis during or after preoperative CRT are rare. For that reason, we conducted this study to evaluate the incidence and the clinical significance of early distant metastasis after preoperative CRT in patients with 
rectal cancer and to provide data that will be useful in determining the evaluation or follow-up protocol for patients whose risk for early distant metastasis is high.

\section{METHODS}

\section{Patient selection and classification}

The medical records of patients who had undergone long-course CRT with neoadjuvant intention for rectal cancer at Korea University Anam Hospital, Seoul, Korea, between June 2007 and July 2015, were retrospectively reviewed. This study was approved by the Institutional Review Board of Korea University Anam Hospital (IRB No. 2018AN0158), and all patients provided written informed consent. Patients who had primary rectal cancer with a pathologically proven adenocarcinoma within $15 \mathrm{~cm}$ of the anal verge, subdivided as lower $(<5 \mathrm{~cm})$, mid $(5-10 \mathrm{~cm})$, and upper $(>10 \mathrm{~cm})$ rectum, were enrolled in this study. Patients who developed distant metastasis within 6 months after completion of CRT were assigned to the early systemic failure group (the EF group). All other patients were assigned to the control group.

\section{Preoperative evaluation and preoperative CRT}

All patients were evaluated preoperatively by using physical examination, total colonoscopy, abdominopelvic computed tomography $(\mathrm{CT})$, chest $\mathrm{CT}$, pelvic magnetic resonance imaging, and routine laboratory tests including tumor markers. Based on these studies, patients without distant metastasis were considered for preoperative CRT.

Preoperative CRT has been performed selectively at our institution; patients with resectable locally advanced rectal cancer including T3 stage and patients with LNs suggesting metastasis including the total mesorectal excision (TME) plane were considered for surgery without preoperative CRT [6]. The indications for preoperative CRT at our hospital were as follows: T4, circumferential resection margin involved or threatened, or suggestive metastasis of lateral pelvic LN, defined as a LN beyond the TME plane such as iliac and obturator LNs, on preoperative staging. Exclusion criteria in this study were as follows: radiotherapy for anal cancer or for recurrent rectal cancer; preoperative shortcourse radiotherapy or postoperative radiotherapy; initial distant metastasis; no restaging work-up after CRT preoperatively or no appropriate follow-up; or preoperative exposure to chemotherapy regimens other than 5-fluorouracil (5-FU) or capecitabine as a radiosensitizer, such as with oxaliplatin, irinotecan, or a target agent.

Patients were treated with neoadjuvant chemoradiation $(5,040$ cGy in 28 fractions) for 5-6 weeks, with intravenous or oral 5-FU (tegafur) or oral capecitabine as a radiosensitizer. Each patient was evaluated by restaging 8-10 weeks later for final decision; then, surgery was performed in most patients unless certain problems, such as distant metastasis or a locally refractory response, developed.

\section{Adjuvant therapy and patient follow-up}

In patients with stage II disease with risk factors or stage III disease postoperatively, oxaliplatin-based adjuvant chemotherapy was performed for 8-12 cycles. In patients who underwent chemotherapy, laboratory tests, including carcinoembryonic antigen (CEA) and abdominopelvic and chest CT, were performed at 3to 4-cycle intervals during chemotherapy, and other examinations, such as sigmoidoscopy or total colonoscopy and positron emission tomography (PET)-CT, were added when necessary. After chemotherapy, follow-up examinations were carried out at 3 -month intervals during the first 2 years postoperatively, at 6-month intervals until 5 years after surgery, and then annually if no evidence of recurrence was found.

\section{Statistical analysis}

Data for the early failure (EF) and the control groups were compared in terms of patient demographics, tumor characteristics, operative and postoperative outcomes, pathologic results, and oncologic outcomes. Descriptive results are presented as medians for continuous outcomes and as frequencies and percentages for categorical outcomes. For nonparametric statistics, Mann-Whitney U-test was used to compare continuous variables, and the chisquare test or Fisher exact test was applied for categorical variables. Five-year overall survival (OS) and recurrence-free survival (RFS) were analyzed using the Kaplan-Meier method, and comparison of survival between groups was performed by using the log-rank test. Statistical analyses were performed using IBM SPSS Statistics ver. 22.0 (IBM Co., Armonk, NY, USA). A P-value < 0.05 was considered statistically significant.

\section{RESULTS}

During the study period, 388 patients with rectal cancer received radiotherapy. Seven patients received radiotherapy for anal cancer or recurrent rectal cancer, 160 received preoperative short-course radiotherapy or postoperative radiotherapy, 72 were found to have an initial distant metastasis, 39 had no restaging work-up or follow-up, and 3 had preoperative exposure to other chemotherapy. Of these, 107 patients were enrolled in the study, and 7 developed early distant metastasis. In the patients with early distant metastasis, the lung was the most common site of distant metastasis ( 4 patients), followed by bone ( 3 patients), liver ( 1 patient), and intramural metastasis of the anal canal (1 patient) (Table 1). The median duration for metastasis was 78.1 days.

Patient demographics are detailed in Table 2. No significant differences were found between the EF and the control groups in terms of age, sex, body mass index, level of tumor location, initial clinical $\mathrm{T}$ and $\mathrm{N}$ stage, or tumor size. In addition, the duration and the doses of radiotherapy were similar. Preoperative CEA was significantly higher in the EF group than in the control group (5 $\mathrm{mg} / \mathrm{mL}$ vs. $2 \mathrm{mg} / \mathrm{mL}, \mathrm{P}=0.010)$. Also, most patients in the control group received intravenous or oral $5-\mathrm{FU}$ as a radiosensitizer, 
Table 1. Detailed description of patients who developed early systemic failure

\begin{tabular}{lcccccccccc}
\hline Patient No. & $\begin{array}{c}\text { Clinical } \\
\text { stage }\end{array}$ & $\begin{array}{c}\text { Clinical } \\
\text { tumor } \\
\text { size }(\mathrm{cm})\end{array}$ & $\begin{array}{c}\text { AV } \\
(\mathrm{cm})\end{array}$ & $\begin{array}{c}\text { Preoperative } \\
\text { CEA } \\
\text { (ng/mL) }\end{array}$ & $\begin{array}{c}\text { Resection of } \\
\text { primary } \\
\text { tumor }\end{array}$ & $\begin{array}{c}\text { Interval from } \\
\text { RT to operation } \\
\text { (day) }\end{array}$ & $\begin{array}{c}\text { Metastatic } \\
\text { lesion }\end{array}$ & $\begin{array}{c}\text { Interval from } \\
\text { RT to metastasis } \\
\text { (day) }\end{array}$ & $\begin{array}{c}\text { Treatment for } \\
\text { metastatic lesion }\end{array}$ & $\begin{array}{c}\text { Follow-up } \\
\text { duration } \\
\text { (mo) }\end{array}$ \\
\hline 1 & CT3N2 & 6.1 & 6 & 11.21 & No & NA & Anal canal, pelvic bone & 56 & Chemotherapy & 3.6 \\
2 & CT4N2 & 4 & 2 & 5.6 & No & NA & Pelvic bone & 32 & None & 7.0 \\
3 & CT3N2 & 6.1 & 8 & 1.40 & Yes & 70 & Lung, liver & 49 & Chemotherapy & 11.2 \\
4 & CT3N0 & 3.4 & 3 & - & Yes & 66 & Lung & 91 & Chemotherapy VATS & 14.5 \\
5 & CT3N2 & 5.2 & 4 & 13.60 & Yes & 59 & Lung & 79 & Chemotherapy VATS & 12.1 \\
6 & CT2N1 & 4 & 2 & 4.62 & Yes & 77 & Multiple bone & 144 & Chemotherapy & 8.8 \\
7 & CT3N2 & 5 & 7 & 3.30 & No & NA & Lung & 96 & Chemotherapy & 17.8 \\
\hline
\end{tabular}

AV, anal verge; CEA, carcinoembryonic antigen; RT, radiotherapy; NA, not applicable; VATS, video-assisted thoracoscopic surgery.

Table 2. Patient demographics and tumor characteristics

\begin{tabular}{|c|c|c|c|}
\hline Characteristic & $\begin{array}{l}\text { Early failure } \\
\text { group } \\
(n=7)\end{array}$ & $\begin{array}{l}\text { Control } \\
\text { group } \\
(n=100)\end{array}$ & P-value \\
\hline Age (yr) & 59 & 60 & 0.955 \\
\hline Sex, male : female & $4: 3$ & $71: 29$ & 0.444 \\
\hline Mean body mass index $\left(\mathrm{kg} / \mathrm{m}^{2}\right)$ & 21 & 23 & 0.116 \\
\hline Mean anal verge (cm) & 4 & 5 & 0.520 \\
\hline Mean preoperative CEA (ng/mL) & 5 & 2 & 0.010 \\
\hline cT stage & & & 0.431 \\
\hline cT2 & $1(14.3)$ & $5(5)$ & \\
\hline cT3 & $5(71.4)$ & $75(75)$ & \\
\hline cT4 & $1(14.3)$ & $20(20)$ & \\
\hline cN stage & & & 0.850 \\
\hline cNO & $1(14.3)$ & $11(11)$ & \\
\hline cN1 & $1(14.3)$ & $26(26)$ & \\
\hline cN2 & $5(71.4)$ & $63(63)$ & \\
\hline Mean clinical tumor size (cm) & 5 & 5 & 0.582 \\
\hline Median RT duration (day) & 39 & 39 & 0.770 \\
\hline Mean RT dose (cGy) & 5,040 & 5,040 & 0.591 \\
\hline Radiosensitizer & & & 0.002 \\
\hline IV 5-FU & $4(57.1)$ & $90(90)$ & \\
\hline Oral 5-FU (tegafur) & $1(14.3)$ & $7(7)$ & \\
\hline Capecitabine & $2(28.6)$ & $3(3)$ & \\
\hline
\end{tabular}

Values are presented as number (\%) unless otherwise indicated.

CEA, carcinoembryonic antigen; RT, radiotherapy; IV, intravenous; 5-FU, 5-fluorouracil.

but patients who used capecitabine were relatively more frequent (EF: $28.6 \%$ vs. control: $3 \%, \mathrm{P}=0.002$ ) in the $\mathrm{EF}$ group.

Only 4 of the 7 patients (57.1\%) with early distant metastasis underwent a resection of the primary rectal lesion. Operative and postoperative outcomes in the patients who received a resection
Table 3. Operative outcomes and postoperative course

\begin{tabular}{lccc}
\hline Variable & $\begin{array}{c}\text { Early failure } \\
\text { group } \\
(\mathrm{n}=7)\end{array}$ & $\begin{array}{c}\text { Control } \\
\text { group } \\
(\mathrm{n}=100)\end{array}$ & P-value \\
\hline Resection of primary tumor & $4(57.1)$ & $100(100)$ & $<0.001$ \\
\hline $\begin{array}{l}\text { Duration to surgery (day) } \\
\text { Type of approach }\end{array}$ & 55 & 0.027 \\
$\quad$ Robot & $4(100)$ & $56(56)$ & 0.471 \\
Laparoscopy & $0(0)$ & $36(36)$ & \\
Open & $0(0)$ & $5(5)$ & \\
Conversion & $0(0)$ & $3(3)$ & \\
Procedure & & & 0.268 \\
\hline LAR & $1(25)$ & $56(56)$ & \\
ISR & $2(50)$ & $34(34)$ & \\
$\quad$ APR & $1(25)$ & $7(7)$ & \\
\hline Hartmann procedure & $0(0)$ & $3(3)$ & \\
Sphincter-saving surgery & $3(75)$ & $90(90)$ & 0.344 \\
Emergency surgery & $0(0)$ & $1(1)$ & 0.843 \\
Mean operative time (min) & 353 & 285 & 0.114 \\
Mean estimated blood loss (mL) & 0 & 0 & 0.132 \\
Morbidity & $3(75)$ & $34(34)$ & 0.098 \\
Anastomotic leakage & $0(0)$ & $10(10)$ & 0.508 \\
Median preoperative hospital stay (day) & 14 & 9 & 0.233 \\
\hline
\end{tabular}

Values are presented as number (\%) unless otherwise indicated.

LAR, low anterior resection; ISR, intersphincteric resection; APR, abdominoperineal resection.

are compared in Table 3 . The resection rate was significant lower in the EF group at $57.1 \%$ compared to the control group at $100 \%$ $(\mathrm{P}<0.001)$. The median duration from CRT to surgery was significantly longer in the EF group (68.0 days vs. 54.7 days, $\mathrm{P}=$ 0.027). No significant differences were found between the groups in terms of type of approach, procedure, rate of sphincter-saving 
Volume 35, Number 2, 2019

Ann Coloproctol 2019;35(2):94-99

Table 4. Pathologic outcomes

\begin{tabular}{|c|c|c|c|}
\hline Variable & $\begin{array}{l}\text { Early failure } \\
\text { group that } \\
\text { underwent } \\
\text { resection } \\
(n=4)\end{array}$ & $\begin{array}{l}\text { Control group } \\
\qquad(\mathrm{n}=100)\end{array}$ & P-value \\
\hline ypT stage & & & 0.104 \\
\hline урT0 & $0(0)$ & $14(14)$ & \\
\hline yрT1 & $0(0)$ & $3(3)$ & \\
\hline ypT2 & $0(0)$ & $23(23)$ & \\
\hline урТ3 & $2(50)$ & $54(54)$ & \\
\hline урT4 & $2(50)$ & $6(6)$ & \\
\hline ypN stage & & & $<0.001$ \\
\hline ypNO & $0(0)$ & $65(65)$ & \\
\hline ypN1 & $1(25)$ & $28(28)$ & \\
\hline ypN2 & $3(75)$ & $7(7)$ & \\
\hline Mean positive LNs & 6 & 0 & 0.006 \\
\hline Mean retrieved LNs & 30 & 13 & 0.017 \\
\hline \multicolumn{4}{|l|}{ ypTNM stage } \\
\hline $0: 1: 2: 3: 4$ & $0: 0: 0: 0: 4$ & $13: 18: 35: 34: 0$ & 0.034 \\
\hline $\begin{array}{l}\text { Mean tumor size after CRT } \\
(\mathrm{cm})\end{array}$ & 2 & 3 & 0.175 \\
\hline Mean PRM (cm) & 22 & 23 & 0.686 \\
\hline Mean DRM (cm) & 2 & 2 & 0.577 \\
\hline \multicolumn{4}{|l|}{ Mandard regression grade } \\
\hline $1: 2: 3: 4: 5$ & $0: 0: 1: 3: 0$ & $5: 3: 10: 16: 0(n=34)$ & 0.240 \\
\hline
\end{tabular}

Values are presented as number (\%) unless otherwise indicated.

LN, lymph node; CRT, chemoradiotherapy; PRM, proximal resection margin; DRM, distal resection margin.

surgery, emergency surgery, operative time, or estimated blood loss. Postoperative morbidity and hospital stay were also similar between the 2 groups.

Among the postoperative pathologic results, the groups were not different in terms of ypT stage and tumor size (Table 4). However, both ypN stage and TNM stage were advanced in the EF group $(\mathrm{P}<0.001$ and $\mathrm{P}=0.034$, respectively), and the numbers of positive and retrieved LNs were significantly higher in the EF group $(\mathrm{P}=0.006$ and $\mathrm{P}=0.017$, respectively).

Adjuvant or palliative chemotherapy or the patients and their oncologic outcomes are described in Table 5. In the control group, local recurrence developed in 9 patients, distant metastasis in 15 patients, and disease recurrence in 23 patients. In the EF group, one patient experienced a local recurrence other than distant metastasis. The median follow-up duration was 11.2 months in the EF group and 33 months in the control group $(\mathrm{P}<0.001)$. A significant difference between the 2 groups was found for RFS $(\mathrm{P}<$ $0.001)$, but not $\mathrm{OS}(\mathrm{P}=0.731)$.
Table 5. Oncologic outcomes

\begin{tabular}{|c|c|c|c|}
\hline Variable & $\begin{array}{l}\text { Early failure } \\
\text { group } \\
(n=7)\end{array}$ & $\begin{array}{l}\text { Control group } \\
(n=100)\end{array}$ & P-value \\
\hline Adjuvant chemotherapy & - & & NA \\
\hline No & - & $19(19)$ & \\
\hline FOLFOX & - & $42(42)$ & \\
\hline IV 5-FU & - & $23(23)$ & \\
\hline Oral 5-FU (tegafur) & - & $9(9)$ & \\
\hline Capecitabine & - & $7(7)$ & \\
\hline Palliative chemotherapy & & - & NA \\
\hline No & $1(14.3)$ & - & \\
\hline FOLFOX & $3(42.9)$ & - & \\
\hline Capecitabine & $1(14.3)$ & - & \\
\hline FOLFIRI + bevacizumab & $2(28.6)$ & - & \\
\hline Disease recurrence & $7(100)$ & $23(23)$ & \\
\hline Local recurrence & $1(14.3)$ & $9(9)$ & \\
\hline Distant metastasis & $7(100)$ & $15(15)$ & \\
\hline Mean follow-up (mo) & 11.2 & 33.0 & 0.001 \\
\hline
\end{tabular}

NA, not applicable; FOLFOX, oxaliplatin-based chemotherapy; IV, intravenous; 5-FU, 5-fluorouracil; FOLFIRI, irinotecan-based chemotherapy.

\section{DISCUSSION}

In our study, early distant metastasis developed in $6.5 \%$ of the patients who had received preoperative CRT. This is a very rare report for early metastasis after preoperative CRT. Kang et al. [7] reported no patients who developed new metastatic lesions before or during surgery in a study comparing open and laparoscopic surgery for mid or low rectal cancer after neoadjuvant CRT. Bujko et al. [8] did not directly report the rate of early distant metastasis in their study comparing long-term oncologic outcomes of shortcourse RT and long-course CRT for patients with rectal cancer; instead, they reported that 140 of the 155 patients allocated to the short-course RT group and 143 of the 157 patients allocated to the CRT group had no distant metastasis at the time of surgery and were alive 30 days after surgery.

We identified the clinical characteristics of patients who developed early distant metastasis. Patients developing early metastasis had a significantly lower rate of primary tumor resection $(57.1 \%)$ compared to the control group, possibly because patients with distant metastasis in the absence of symptoms frequently receive palliative chemotherapy without surgery. In addition, the time from CRT to surgery may have been longer in the EF group due to the design of new treatment plans for unexpected distant metastasis.

In this study, capecitabine as a radiosensitizer was frequently used in the EF group. The result could be misinterpreted to mean that capecitabine has weaker systemic effects than 5-FU, which 
differs from the results of previous studies. In general, capecitabine not only shows better oncologic outcomes than 5 -FU at a systemically effective dose as an adjuvant treatment $\left(1,250 \mathrm{mg} / \mathrm{m}^{2}\right.$ twice daily), but its oncologic superiority continues at a lower dose (825 $\mathrm{mg} / \mathrm{m}^{2}$ twice daily) as a radiosensitizer for CRT $[9,10]$. Because the results in our study may have statistical bias due to the small number of patients in the EF group, further study including a larger number of patients is needed.

The lung was the most common site of distant metastasis in the EF group, which was unexpected given that, in general, the liver is the most common metastatic site of colorectal cancer. This difference might be attributed to the locations of the tumor levels in the lower rectum, which were a median of $4 \mathrm{~cm}$ above the anal verge. Generally, lymphatic drainage of the mid to lower rectum passes through the lateral pathway and drains directly to the lung [11, 12]. Bone metastasis was also common, second to lung metastasis, and both of these metastases are very aggressive, with short life expectancy $[13,14]$. Thus, the metastatic lesions in the EF group indicated their potential aggressiveness, which was also represented by poor nodal response to preoperative CRT.

The possibility should be considered that early distant metastasis may arise from metastasis missed on initial imaging studies for work-up. Abdominopelvic and chest CT, as well as PET-CT, can be read as false negative for a distant metastasis with a small size $[15,16]$. In particular, indeterminate nodules are common on chest CT, and pulmonary metastasis can be difficult to assess $[6$, 17]. Radiologic methods are limited in their ability to detect microscopic metastases. Accordingly, a relevant radiological diagnosis should be a prerequisite for formulating an appropriate treatment plan, as well as a follow-up imaging work-up.

The challenge remains to identify early which patients will experience a poor local response to CRT and develop a distant metastasis. We found no significant differences in any of the patients' demographics or tumor characteristics between the EF and the control groups. If a meaningful intrinsic factor associated with the response to CRT, such as a gene expression profile, could be found, that factor could help in planning neoadjuvant therapy. However, studies on predictive factors are lacking. Some studies have suggested possible factors, but most of these remain at the experimental level $[18,19]$.

Accurate predictions of the responses to CRT or to craft tailored treatments are still not possible. The strategy of avoiding CRT due to concerns for early systemic failure may cause more injury than good for patients given that the rate of early systemic failure was very low in our study, at $6.5 \%$. Therefore, a realistic alternative would be to conduct intensive follow-up for early detection of a distant metastasis during CRT, although debate is still ongoing regarding the utility of restaging images after neoadjuvant treatment for changing treatment strategy [20,21]. Along with initial studies before CRT and preoperative restaging work-ups after CRT, additional abdominopelvic and chest CT could be added during the interval from 8 to 10 weeks after CRT.
This study had some limitations. First, it was a retrospective analysis with several biases and a small number of patients in the EF group. In particular, many patients received short-course radiotherapy at our institution and were excluded from this study. The results might have been different if they had also received CRT. Above all, evaluating the risk factors for early systemic failure was difficult because of the large difference in the numbers of patients between the EF and the control groups. Moreover, molecular biomarkers, such as epidermal growth factor receptor, Kras/N-ras, microsatellite instabilities, and caudal type homeobox-2, were not analyzed due to insufficient data. Nevertheless, our study is very valuable because data on the clinical characteristics of early distant metastasis after CRT are rare.

In conclusion, unlike our concern, in this study, early distant metastasis rarely developed after CRT for the treatment of patients with rectal cancer. Patients who developed an early metastasis also had poor nodal responses to CRT, with low primary tumor resection rates and very poor oncologic results. For early detection and treatment, intensive follow-up imaging work-ups can be considered during the period between CRT and surgery. Furthermore, additional study is needed to identify intrinsic factors helpful for predicting the responses of patients to CRT and for tailoring treatment.

\section{CONFLICT OF INTEREST}

No potential conflict of interest relevant to this article was reported.

\section{REFERENCES}

1. Sauer R, Becker H, Hohenberger W, Rödel C, Wittekind C, Fietkau R, et al. Preoperative versus postoperative chemoradiotherapy for rectal cancer. N Engl J Med 2004;351:1731-40.

2. Gérard JP, Conroy T, Bonnetain F, Bouché O, Chapet O, ClosonDejardin MT, et al. Preoperative radiotherapy with or without concurrent fluorouracil and leucovorin in T3-4 rectal cancers: results of FFCD 9203. J Clin Oncol 2006;24:4620-5.

3. Benson AB 3rd, Bekaii-Saab T, Chan E, Chen YJ, Choti MA, Cooper HS, et al. Rectal cancer. J Natl Compr Canc Netw 2012; 10:1528-64.

4. Glynne-Jones R, Falk S, Maughan TS, Meadows HM, SebagMontefiore D. A phase I/II study of irinotecan when added to 5-fluorouracil and leucovorin and pelvic radiation in locally advanced rectal cancer: a Colorectal Clinical Oncology Group Study. Br J Cancer 2007;96:551-8.

5. Rödel C, Graeven U, Fietkau R, Hohenberger W, Hothorn T, Arnold $\mathrm{D}$, et al. Oxaliplatin added to fluorouracil-based preoperative chemoradiotherapy and postoperative chemotherapy of locally advanced rectal cancer (the German CAO/ARO/AIO-04 study): final results of the multicentre, open-label, randomised, phase 3 trial. Lancet Oncol 2015;16:979-89. 
6. Baek SJ, Kim SH, Kwak JM, Cho JS, Shin JW, Amar AH, et al. Indeterminate pulmonary nodules in rectal cancer: a recommendation for follow-up guidelines. J Surg Oncol 2012;106:481-5.

7. Kang SB, Park JW, Jeong SY, Nam BH, Choi HS, Kim DW, et al. Open versus laparoscopic surgery for mid or low rectal cancer after neoadjuvant chemoradiotherapy (COREAN trial): short-term outcomes of an open-label randomised controlled trial. Lancet Oncol 2010;11:637-45.

8. Bujko K, Nowacki MP, Nasierowska-Guttmejer A, Michalski W, Bebenek M, Kryj M. Long-term results of a randomized trial comparing preoperative short-course radiotherapy with preoperative conventionally fractionated chemoradiation for rectal cancer. Br J Surg 2006;93:1215-23.

9. Yoney A, Isikli L. Preoperative chemoradiation in locally advanced rectal cancer: a comparison of bolus 5-fluorouracil/leucovorin and capecitabine. Saudi J Gastroenterol 2014;20:102-7.

10. Kim DY, Jung KH, Kim TH, Kim DW, Chang HJ, Jeong JY, et al. Comparison of 5-fluorouracil/leucovorin and capecitabine in preoperative chemoradiotherapy for locally advanced rectal cancer. Int J Radiat Oncol Biol Phys 2007;67:378-84.

11. Pihl E, Hughes ES, McDermott FT, Johnson WR, Katrivessis H. Lung recurrence after curative surgery for colorectal cancer. Dis Colon Rectum 1987;30:417-9.

12. Scheele J, Altendorf-Hofmann A, Stangl R, Gall FP. Pulmonary resection for metastatic colon and upper rectum cancer. Is it useful? Dis Colon Rectum 1990;33:745-52.

13. Baek SJ, Hur H, Min BS, Baik SH, Lee KY, Kim NK. The characteristics of bone metastasis in patients with colorectal cancer: a long-term report from a single institution. World J Surg 2016;40: 982-6.

14. Khattak MA, Martin HL, Beeke C, Price T, Carruthers S, Kim S, et al. Survival differences in patients with metastatic colorectal cancer and with single site metastatic disease at initial presenta- tion: results from South Australian clinical registry for advanced colorectal cancer. Clin Colorectal Cancer 2012;11:247-54.

15. Zerhouni EA, Rutter C, Hamilton SR, Balfe DM, Megibow AJ, Francis IR, et al. CT and MR imaging in the staging of colorectal carcinoma: report of the Radiology Diagnostic Oncology Group II. Radiology 1996;200:443-51.

16. Lu YY, Chen JH, Ding HJ, Chien CR, Lin WY, Kao CH. A systematic review and meta-analysis of pretherapeutic lymph node staging of colorectal cancer by 18 F-FDG PET or PET/CT. Nucl Med Commun 2012;33:1127-33.

17. Quyn AJ, Matthews A, Daniel T, Amin AI, Yalamarthi S. The clinical significance of radiologically detected indeterminate pulmonary nodules in colorectal cancer. Colorectal Dis 2012;14:82831.

18. He HL, Lee YE, Shiue YL, Lee SW, Lin LC, Chen TJ, et al. PLA2G2A overexpression is associated with poor therapeutic response and inferior outcome in rectal cancer patients receiving neoadjuvant concurrent chemoradiotherapy. Histopathology 2015;66:991-1002.

19. Lee YE, He HL, Shiue YL, Lee SW, Lin LC, Wu TF, et al. The prognostic impact of lipid biosynthesis-associated markers, HSD17B2 and HMGCS2, in rectal cancer treated with neoadjuvant concurrent chemoradiotherapy. Tumour Biol 2015;36:7675-83.

20. Ayez N, Alberda WJ, Burger JW, Eggermont AM, Nuyttens JJ, Dwarkasing RS, et al. Is restaging with chest and abdominal CT scan after neoadjuvant chemoradiotherapy for locally advanced rectal cancer necessary? Ann Surg Oncol 2013;20:155-60.

21. Jaffe TA, Neville AM, Bashir MR, Uronis HE, Thacker JM. Is follow-up CT imaging of the chest and abdomen necessary after preoperative neoadjuvant therapy in rectal cancer patients without evidence of metastatic disease at diagnosis? Colorectal Dis 2013;15:e654-8. 